\title{
Improved high temperature strength of Copper-Graphene Composite
}

\section{Material}

\author{
Xueliang Wanga , Junjun, Li ${ }^{\mathrm{a}}$, Yaping Wang, b,* \\ ${ }^{a}$ MOE Key Laboratory for Nonequilibrium Synthesis and Modulation of Condensed Matter, School of Science, Xi'an Jiaotong \\ University, Xi'an 710049, PR China \\ ${ }^{b}$ State Key Laboratory for Mechanical Behavior of Materials, Xi'an Jiaotong University, Xi'an 710049, PR China
}

\begin{abstract}
The strength of polycrystalline materials at high temperatures is limited due to their poor resistance to grain boundary motion. A strategy to anchor the grain boundary of copper in 2-dimensional curvature by graphene was proposed and the copper-graphene composite was therefore fabricated. It was found that the hardness of $\mathrm{Cu}-0.5 \mathrm{wt} \%$ graphene $(\mathrm{GN})$ composite is almost same with that of $\mathrm{Cu}-0.5 \mathrm{wt} \%$ graphite (GP) composite between room temperature and $450{ }^{\circ} \mathrm{C}$. However, the hardness of $\mathrm{Cu}-\mathrm{GN}$ composite improves significantly above $450{ }^{\circ} \mathrm{C}$ and is nearly twice of that of $\mathrm{Cu}-\mathrm{GP}$ composite at $600{ }^{\circ} \mathrm{C}$, indicating the hindrance effect of grphene on the atom diffusion across grain boundary at high temperatures. On the other hand, the thermal expansion coefficient is lower for $\mathrm{Cu}-\mathrm{GN}$ composite compared with that of $\mathrm{Cu}-\mathrm{GP}$ composite, and the electrical conductivity of the $\mathrm{Cu}-0.5 \mathrm{wt} \%$ GN composite remains 95.9 IACS\%.
\end{abstract}

Keywords: High temperature; Hardness; Grain boundary; Diffusion; Graphene

\section{Introduction}

The decreased strength of polycrystalline materials at high temperatures is considered to be attributed to the grain boundary motion, which is thermally activated with the models of grain boundary migration ${ }^{[1,2]}$, grain rotation ${ }^{[3,4]}$ or grain boundary transformation ${ }^{[5]}$. The grain boundary motion at high temperatures is actually the intragranular diffusivity of atoms from one site to different sites or intergranular diffusivity of atoms from one grain to the adjacent ones, which finally results in the decreased strength of polycrystalline materials at high temperatures.

In order to enhance the high temperature strength of polycrystalline materials, precipitating particles and second-phase additives are usually employed to drag grain boundary motion and pin dislocation sliding at high temperatures. Ken et al. ${ }^{[6]}$ reported the hardness of $\mathrm{Cu}-8 \mathrm{Cr}-4 \mathrm{Nb}$ alloy retained $90 \mathrm{HV}$ at $1323 \mathrm{~K}$, which was mainly attributed to the grain boundary pinning of $\mathrm{Cr}_{2} \mathrm{Nb}$

${ }^{*}$ Corresponding author.

E-mail addresses: ypwang@xjtu.edu.cn (Y.P. Wang), wx1562381440@126.com (X. L. Wang) 
precipitates. According to Sebastianet al. ${ }^{[7]}$, the microstructure stability of Ni-carbon nanotube (CNT) composite was enhanced by CNTs by pinning the grain boundary during heat treatment, which results in a high retention of hardness after annealing. The traditional strengthening mechanism of polycrystalline material is mainly particle dispersion strengthening, while strengthening by hindering atom diffusion across grain boundary hasn't been reported yet. Graphene has attracted ever-increasing attention due to its excellent physical and mechanical properties. Especially, its unique 2D structure might make it suitable for hindering the atom diffusion across grain boundary at high temperatures.

In this letter, copper-graphene composite with graphene distributed in copper grain boundary was fabricated. The hardness was tested from $25^{\circ} \mathrm{C}$ to $600{ }^{\circ} \mathrm{C}$. The thermal expansion coefficient (CTE) and electrical conductivity were measured. The copper-graphite composite was also prepared for comparison.

\section{Experimental}

The graphene was synthesized by the modified Hummers methods ${ }^{[8]}$, in which the graphite particles $(99.5 \%,<15 \mu \mathrm{m})$ were employed as raw material. Copper powders $(99.9 \%,<75 \mu \mathrm{m})$ were taken as matrix material. The prepared graphene were ultrasonicated in ethyl alcohol solution for $15 \mathrm{~h}$, and then mixed with copper powders into slurry under magnetic stirring for $20 \mathrm{~h}$. Finally, the mixture was vacuum dried at $80{ }^{\circ} \mathrm{C}$ for $24 \mathrm{~h}$. The mixture were first compacted into $\varphi 35 \times 10 \mathrm{~mm}$ billets, which were then consolidated by vacuum sintering at $950{ }^{\circ} \mathrm{C}$, further consolidated by hot-pressing at $600{ }^{\circ} \mathrm{C}$ under $30 \mathrm{MPa}$. For comparison, copper composites reinforced with the same mass content of graphite as well as unreinforced pure copper specimens were prepared in the same process.

The morphology was characterized by scanning electron microscopy (SEM, JEOL JSM-7000F). Details on the interphase boundary were characterized by transmission electron microscopy (TEM, JEOL JEM-2100). The graphene was investigated by Raman spectroscopy (HORIBA, hr800) using an excitation wavelength of $514 \mathrm{~nm}$. The hardness measurement was implemented by a Vickers Hardness Tester (HTV-PHS30, Archimedes, Ltd., Beijing, China) under argon atmosphere with a load of $500 \mathrm{~g}$ for $15 \mathrm{~s}$, from $25^{\circ} \mathrm{C}$ to $600^{\circ} \mathrm{C}$ within an interval of $50^{\circ} \mathrm{C}$. The thermal expansion coefficient (CTE) was determined by TA Instruments-Dolatometer (DIL802) from $100{ }^{\circ} \mathrm{C}$ to $750{ }^{\circ} \mathrm{C}$ with a heating rate of 5 ${ }^{\circ} \mathrm{C} / \mathrm{min}$. The electrical conductivity was tested by a digital conductivity meter (D60K-1201).

\section{Results and discussion}

Fig. 1(a) shows the TEM image of the prepared graphene. There are some wrinkles on the 
graphene surface, demonstrating its excellent flexibility. Fig. 1(b) shows the Raman spectroscopy of the graphene, graphene oxide, and graphite. The gradual increased ratio of $I_{D} / I_{G}$ indicates that the disorder density in the graphene increased during the oxidation and reduction process.
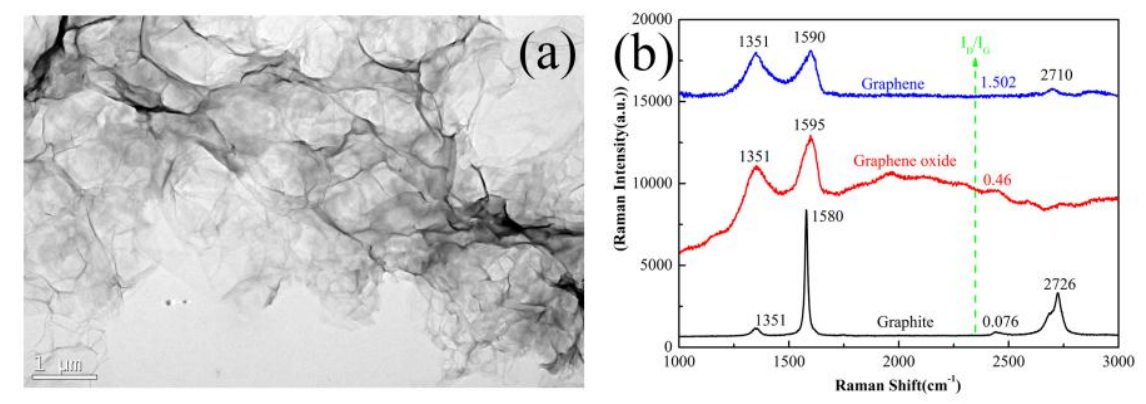

Fig.1. TEM image of the prepared graphene (a), Raman spectrum of graphene, graphene oxide, and graphite (b).

Fig. 2(a) shows the SEM image of Cu-GN composite. It is difficult to distinguish the graphene from the copper matrix at low magnification due to the nano-size of graphene. In Fig. 2(b), the inset images magnified from the dotted boxes 1 and 2 reveal that the graphene are randomly distributed in the grain boundary of copper matrix. The grain size distribution of $\mathrm{Cu}-\mathrm{GN}$ and $\mathrm{Cu}-\mathrm{GP}$ composites are shown in Fig. 2(c) and (f), the average grain size of $\mathrm{Cu}-\mathrm{GN}$ composite is smaller than that of $\mathrm{Cu}-\mathrm{GP}$ composite, indicating more grain boundaries are formed by GN in the $\mathrm{Cu}-\mathrm{GN}$ composite. SEM image in Fig. 2(d) shows the graphite particles are homogeneously dispersed in the copper grain boundary. The grain boundary spacing of copper is increased to several micrometers by the graphite particle (dotted ellipse in Fig. 2(e)), which is considered to have a negative effect on grain boundary strengthening.

Fig. 3(a) is the HRTEM image of Cu-GN composite. The graphene with ultrahigh specific surface area anchored on the copper grain is considered to form considerable interphase. The inset image shows the interphase boundary between copper and graphene, which is of high compatibility and is closely bonded. The thickness of the graphene anchoring on the surface of copper as shown in the inset image is $\sim 5 \mathrm{~nm}$, which is considered to have little negative effect on grain boundary strengthening. Fig. 3(b) shows the curved interphase boundary between copper grain boundary and graphite. The lattice fringe of graphite in the interphase boundary is (003), the inset image is the corresponding selected diffraction pattern of Fig. 3(b), which is ascribed to the (111) and (311) crystallographic plane of copper in the interphase boundary. 

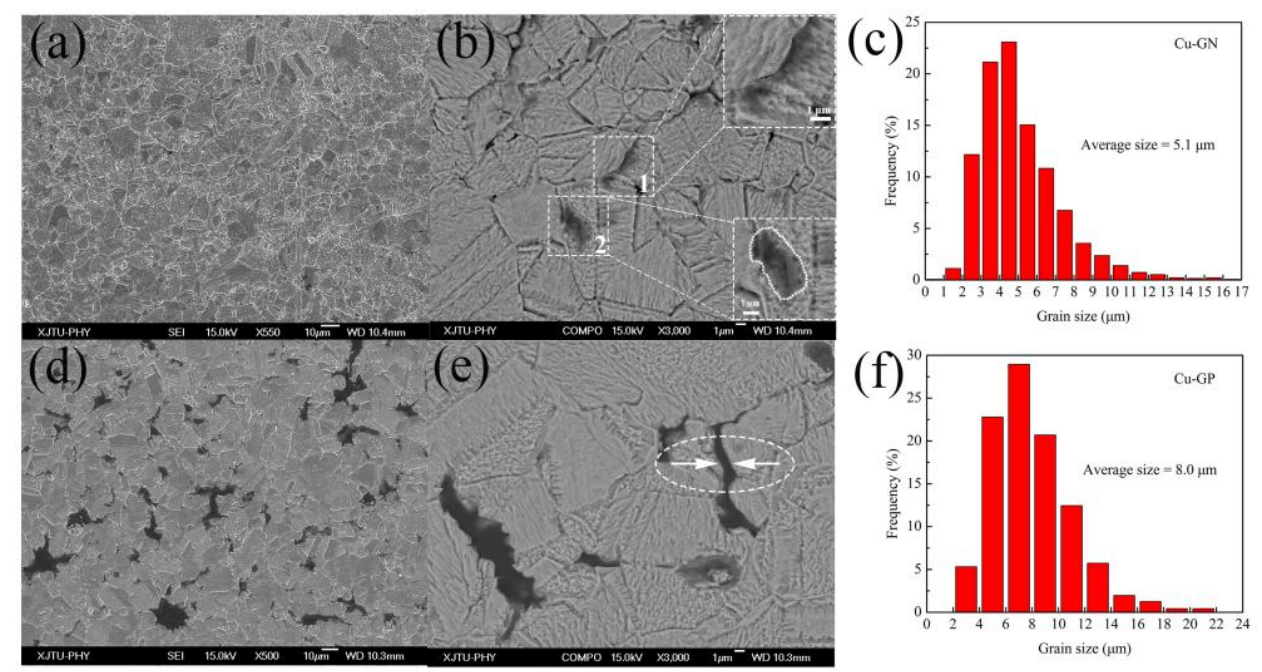

Fig.2. SEM images (a), (b) and grain size distribution of Cu-GN composite (c), the inset images in (b) indicate the 2D GN in box 1 is perpendicular to the image while in box 2 it is parallel; SEM images (d), (e) and grain size distribution of Cu-GP composite (f).

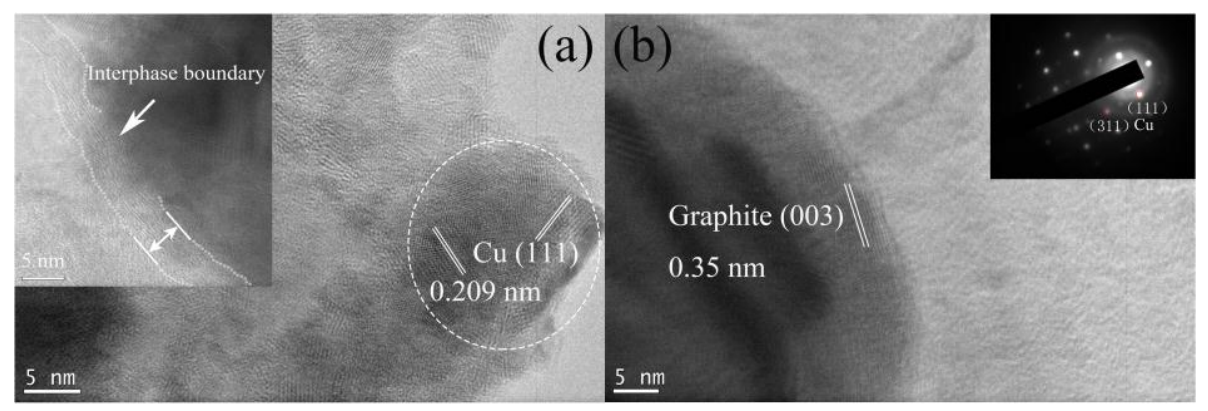

Fig.3. HRTEM image of Cu-GN composite (a), and Cu-GP composite (b).

The Vickers Hardness of copper matrix composites is shown in Fig. 4 (a), the hardness is similar for $\mathrm{Cu}-\mathrm{GN}$ and $\mathrm{Cu}-\mathrm{GP}$ composites below $450{ }^{\circ} \mathrm{C}$. While the hardness is of significant difference when the temperature exceeds $450{ }^{\circ} \mathrm{C}$, it retained $60 \mathrm{HV}$ at $600{ }^{\circ} \mathrm{C}$ for the $\mathrm{Cu}-\mathrm{GN}$ composite, which is twice of that of the $\mathrm{Cu}-\mathrm{GP}$ composite $(30 \mathrm{HV})$. It is considered that the graphene distributed in copper grain boundary acts as 2D barrier, which is more effective in hindering the atom diffusion across grain boundary, as shown in Fig.4 (b (1)). Meanwhile, the graphene with higher aspect ratio is thought to produce greater drag force on grain rotation and grain boundary motion ${ }^{[9,10]}$. Hence, the grain boundary remains stable at high temperatures, and the grain boundary strengthening is considered still effective at elevated temperatures. On the other hand, the rapid decrease in hardness from $450{ }^{\circ} \mathrm{C}$ for the $\mathrm{Cu}-\mathrm{GP}$ composite is mainly due to the failure of grain boundary strengthening caused by grain boundary motion at high temperatures, because atoms in grain boundary are easier to diffuse across the discontinuous interphase formed by the isolated graphite particle, as shown in Fig.4 (b (2)). 

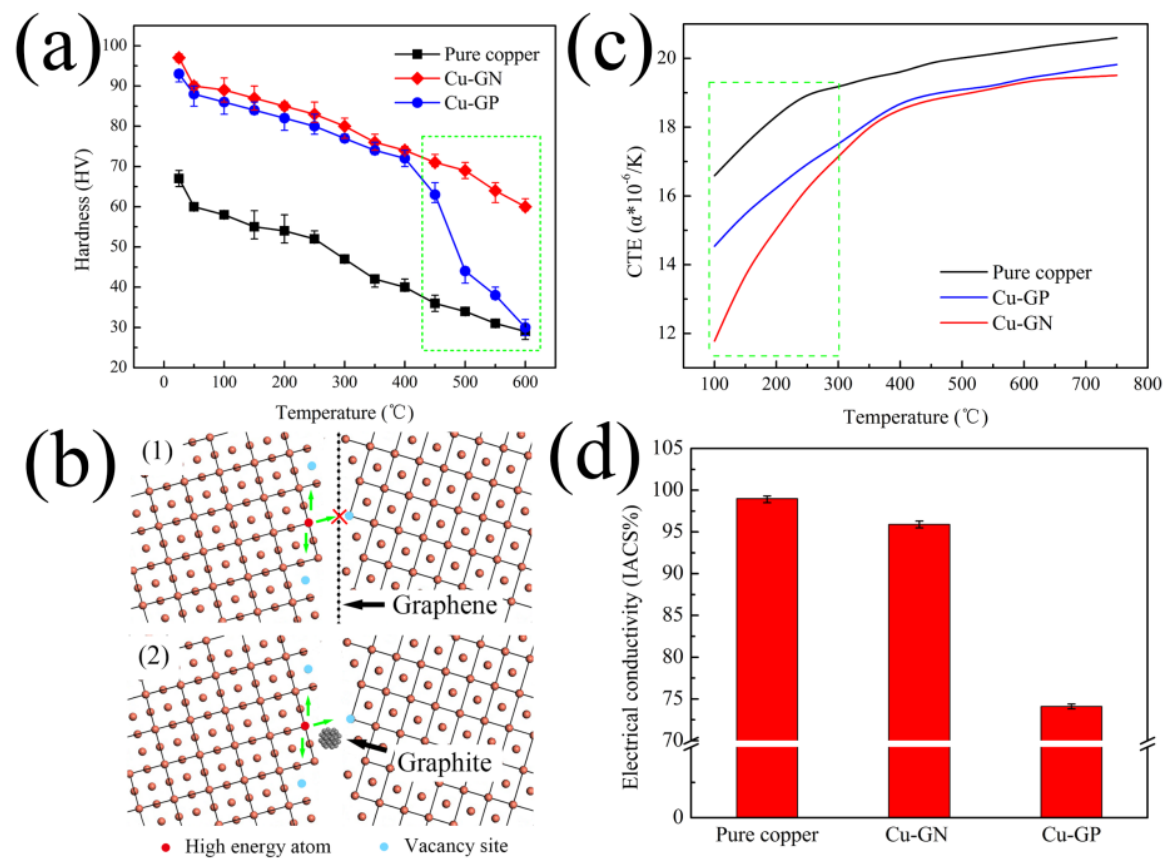

Fig.4. Hardness $v s$. temperature curves of copper matrix composites (a); schematic diagrams of the hindrance of atom diffusion generated by graphene and graphite (b); CTE vs. temperature curves (c), and electrical conductivity of copper matrix composites (d).

As shown in Fig. 4 (c), the obvious reduction in CTE for Cu-GN composite compared with $\mathrm{Cu}-\mathrm{GP}$ composite between $100{ }^{\circ} \mathrm{C}$ and $300{ }^{\circ} \mathrm{C}$ is also considered to be attributed to the more effective drag force on grain boundary motion produced by graphene at elevated temperatures. The strip-like graphene with much higher aspect ratio anchored on the copper grain surface to form a continuous elongated interphase boundary. What's more, greater compression stress is applied on the copper grain growth by the graphene for its negative $\mathrm{CTE}^{[11]}$, which restrained the expansion of copper grain to a large extent in the initial heating stage. Consequently, the enhanced high temperature hardness and the decreased $\mathrm{CTE}$ of $\mathrm{Cu}-\mathrm{GN}$ composite are considered mainly attributed to the more effective hindrance of atom diffusion across grain boundary as well as the more pronounced drag force on grain boundary motion produced by graphene at high temperatures. In addition, the electrical conductivity of $\mathrm{Cu}-\mathrm{GN}$ composite shown in Fig. 4 (d) remains 95.9 IACS\%, which is much higher than that of $\mathrm{Cu}-\mathrm{GP}$ composite (74.1 IACS\%).

\section{Conclusions}

The copper-graphene composite with graphene anchored on the copper grain boundary is fabricated. The hardness of $\mathrm{Cu}-0.5 \mathrm{wt} \% \mathrm{GN}$ composite is almost same with that of $\mathrm{Cu}-0.5 \mathrm{wt} \% \mathrm{GP}$ composite between room temperature and $450^{\circ} \mathrm{C}$. However, the hardness of $\mathrm{Cu}-\mathrm{GN}$ composite 
improves significantly above $450{ }^{\circ} \mathrm{C}$ and is nearly twice of that of $\mathrm{Cu}-\mathrm{GP}$ composite at $600{ }^{\circ} \mathrm{C}$. The $\mathrm{CTE}$ is lower for $\mathrm{Cu}-\mathrm{GN}$ composite compared with $\mathrm{Cu}-\mathrm{GP}$ composite. The enhanced high temperature hardness and the reduced CTE of Cu-GN composite are attributed to the effective hindrance of atom diffusion across grain boundary by graphene.

\section{Acknowledgments}

The authors acknowledge the financial support of the National Science Foundation of China (Nos.51171146 and 51101177) and the Program for Key Science and Technology Innovative Research Team of Shaanxi Province (No. 2013KCT-05). 


\section{References}

[1] T. J. Rupert, D. S. Gianola, Y. Gan, K. J. Hemker, Experimental Observations of Stress-Driven Grain Boundary Migration, Science 326.5960(2009) 1686-1690.

[2] M. Upmanyu, D. J. Srolovitz, A. E. Lobkovsky, J. A. Warren, W. C. Carter, Simultaneous grain boundary migration and grain rotation, Acta Mater. 54(7) (2006) 1707-1719.

[3] M. Dorel, Y. Vesselin, W. Dieter, S. R. Phillpot, Scaling Behavior of Grain-Rotation-Induced Grain Growth, Phys. Rev. Lett. 89.20(2002) 111-118.

[4] T. Gorkaya, K. D. Molodov, D. A. Molodov, G. Gottstein, Concurrent grain boundary motion and grain rotation under an applied stress, Acta Mater. 59.14(2011) 5674-5680.

[5] S. N. Zhevnenko, E. I. Gershman, Grain boundary phase transformation in $\mathrm{Cu}-\mathrm{Co}$ solid solutions, J. Alloys Compd. 536.4(2012) 554-558.

[6] K. R. Anderson, J. R. Groza, R. L. Dreshfield, D. Ellis, High-performance dispersion-strengthened Cu8Cr4Nb alloy, Metall. Mater. Trans. A, 26(9) (1995) 2197-2206.

[7] S. Sebastian, L. Federico, S. Flavio, P. Reinhard, M. Frank, Microstructural thermal stability of CNT-reinforced composites processed by severe plastic deformation, Mater. Sci. Eng., A 626 3(2015) $122-127$

[8] B. K. Ong, H. L. Poh, C. K. Chua, M. Pumera, Graphenes Prepared by Hummers, Staudenmaier and Hofmann Methods for Analysis of TNT-Based Nitroaromatic Explosives in Seawater, Electroanalysis 24.11(2012) 2085-2093.

[9]G“unter Gottstein, Lasar S. Shvindlerman, grain boundary migration in metal, Sec ed., CRC Press, Boca Raton, 2010.

[10] L. Vanherpe, N. Moelans, B. Blanpain, S. Vandewalle, Pinning effect of spheroid second-phase particles on grain growth studied by three-dimensional phase-field simulations, Comp. Mat. Sci. 49 (2010) 340 .

[11] D. Yoon, Y. W. Son, H. Cheong, Negative Thermal Expansion Coefficient of Graphene Measured by Raman Spectroscopy. Nano Lett. 11.8 (2011) 3227-31. 